\title{
Thoracic duct changes in schistosomal hepatic fibrosis
}

\author{
A. M. SADEK, A. ABOUL-ENEIN, E. HASSENEIN, AND A. ISMAIL \\ From the Departments of Surgery and Radiology, University of Alexandria, UAR
}

SUMMARY The changes in the thoracic duct were studied in schistosomatic hepatic fibrosis, particularly in cases with ascites. The postmortem findings, lymphangiography, and clinical thoracic duct cannulation showed that, particularly in cases with ascites, the thoracic duct is dilated, pressure within is raised, and the lymph flow is increased. The significance of these findings is discussed in relation to the site and the treatment of ascites.

Dumont and Mulholland (1962) observed that cannulation of the thoracic duct in patients suffering from Laennec's cirrhosis effected results comparable with porta caval shunt. Madden, Lore, Gerold, and Ravid (1954) showed that in cirrhosis there is an obstruction to the hepatic venous outflow which produces an increase in the sinusoidal pressure, and Hyatt, Lawrence, and Smith (1955) demonstrated that the augmented sinusoidal pressure led to an increase in hepatic lymph formation. The same authors compared the protein content of hepatic lymph to that of plasma and found it to be similar. The absorption of fluid rich in protein in the peritoneal cavity is mainly by the lymphatics (Allen and Vogt, 1937; Hahn, Miller, Robscheit-Robbins, Bale, and Whipple, 1944; Courtice and Steinbeck, 1950, 1951): the chief peritoneal lymphatic drainage pathways are the diaphragmatic vessels (Higgins and Graham, 1929; Lemon and Higgins, 1929; Simer, 1944 and 1948), which in turn pass to the thoracic and right ducts (Bolton, 1921). Dumont and Witte (1966) showed that the thoracic duct flow in patients suffering from Laennec's cirrhosis is 10 to 15 times that of the normal, and that the thoracic duct becomes dilated with incompetent valves.

In contrast to the postsinusoidal obstruction in cirrhosis, schistosomal hepatic fibrosis carries a presinusoidal obstruction (Ramos, Saad, and
Leser, 1964; Salah, 1962; Badawi, Nomeir, and Zaher, 1962), as judged from the intrasplenic and wedged hepatic vein pressures. The present study was undertaken to study the changes in the abdomino-thoracic lymphatics in schistosomal hepatic fibrosis.

\section{Methods and Material}

The work comprised postmortem studies, lymphangiography, and thoracic duct cannulation.

\section{POSTMORTEM STUDY}

Thirty-six cadavers were selected. Complete clinical data and investigations were recorded. Ten were cases of schistosomal hepatic fibrosis with ascites and five with variceal haemorrhage; five were chronic schistosomal hepatic fibrosis with neither ascites nor haemorrhage; six cases were of heart failure; and 10 were chosen as controls in which the cause of death was massive coronary occlusion or trauma.

The thoracic duct in each was exposed by the method of Van Pernis (1949). Before dissection, one of the lumbar trunks was cleared, cannulated with a fine polythene tube and injected with warm barium gelatin solution at a pressure of 
15 to $20 \mathrm{~cm}$. After complete filling of the thoracic duct, the specimen was cooled in ice-cold solution at $4^{\circ} \mathrm{C}$. The thoracic duct was completely separated from the surrounding tissue by careful dissection, taking care in identifying the small tributaries which were sometimes found to be communicating with the venous system or lymphatic channels. The volume of the isolated thoracic duct was determined by immersing it in a calibrated vessel and noting the amount of fluid displaced.

\section{LYMPHANGIOG R A PHY}

Twenty-one cases were submitted to the investigation. Five were normal and acted as controls, 10 were of schistosomal hepatic fibrosis with ascites, and six were of the same condition but with variceal haemorrhage.

The inguinal lymph nodes were used as the portal of entry, following the method of Hall and Krementz (1967), through a 21-gauge needle at a rate of $1 \mathrm{ml}$ every 10 minutes. Each patient received $20 \mathrm{ml}$ of iodized oil pumped automatically on both sides.

\section{THORACIC DUCT CANNULATION}

Ten cases of schistosomal hepatic fibrosis with ascites were operated upon. General or local anaesthesia was used. The thoracic duct was exposed on the left side of the neck and cannulated with a polythene tube of $1 \mathrm{~mm}$ internal diameter. The lymph was allowed to flow freely into a sterilized bag. The pressure in the thoracic duct was determined by connecting the end of the tube to a spinal manometer containing heparinized saline and using the clavicle as a base line. The reading obtained is referred to as the occlusive thoracic duct pressure. In a few cases, a non-occlusive thoracic pressure was obtained by cannulating one of the collaterals of the thoracic duct before cannulation. The lymph flow per minute was determined, and samples of lymph
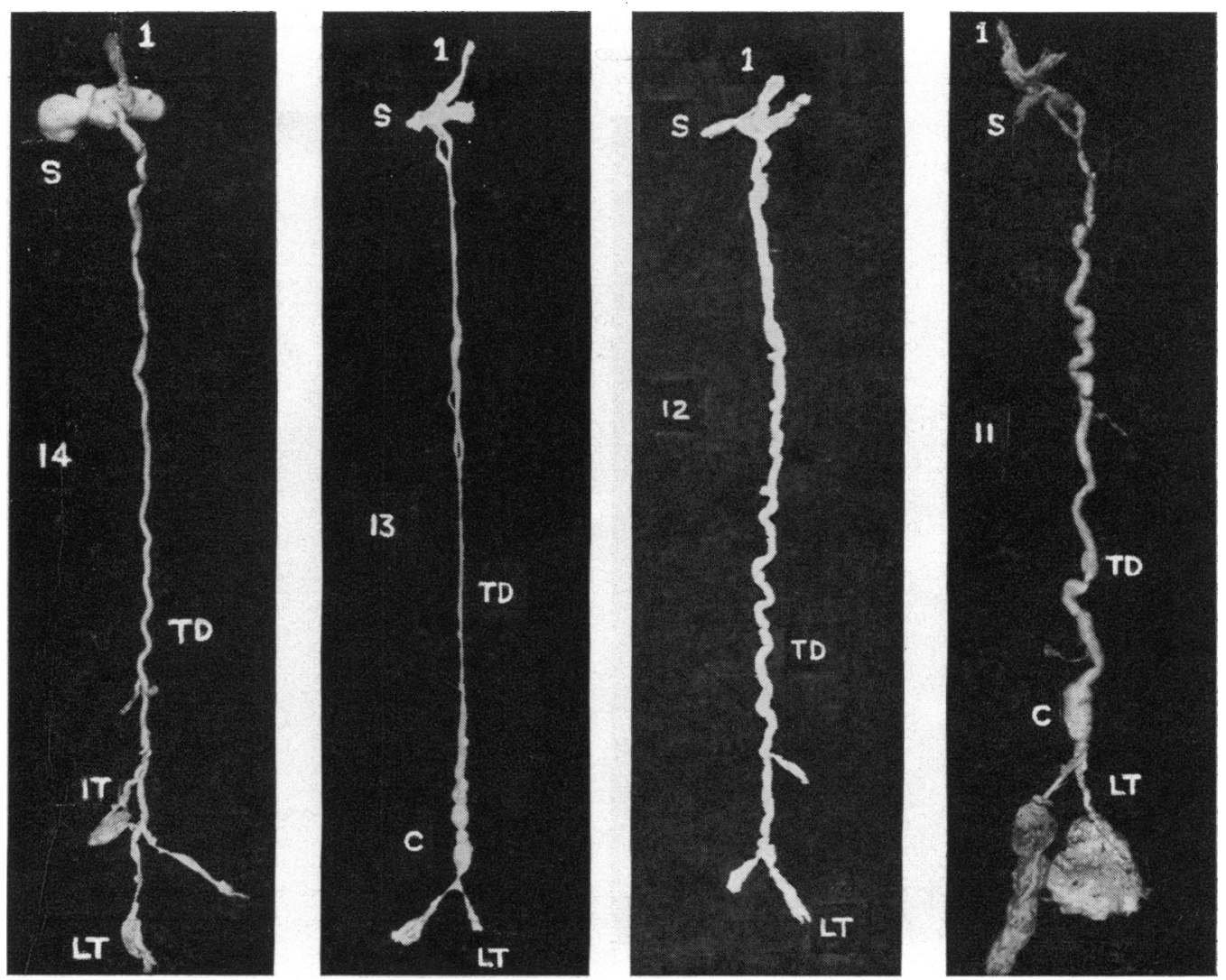


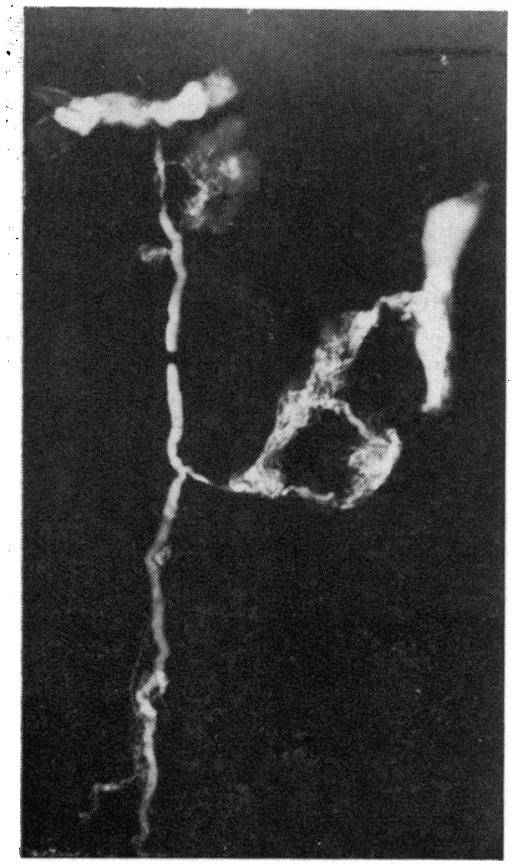

Volume of affected T.D./ volume of normal T.D.

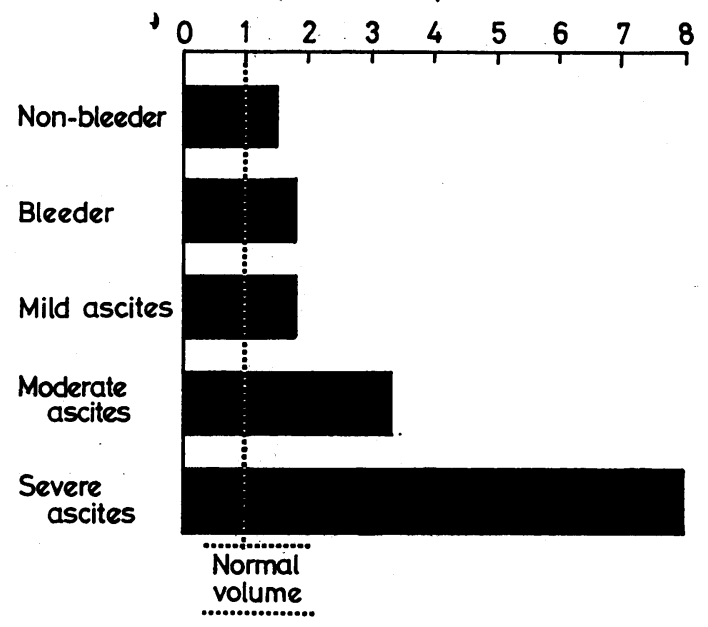

FIG. 2 Postmortem lymphangiograph of dissected thoracic duct from a haemophiliac. There is a lymphatico-venous communication with the azygos vein.

FIG. 3 Diagram showing the increase in volume of the thoracic duct in the various clinical presentations of schistosomal hepatic fibrosis.
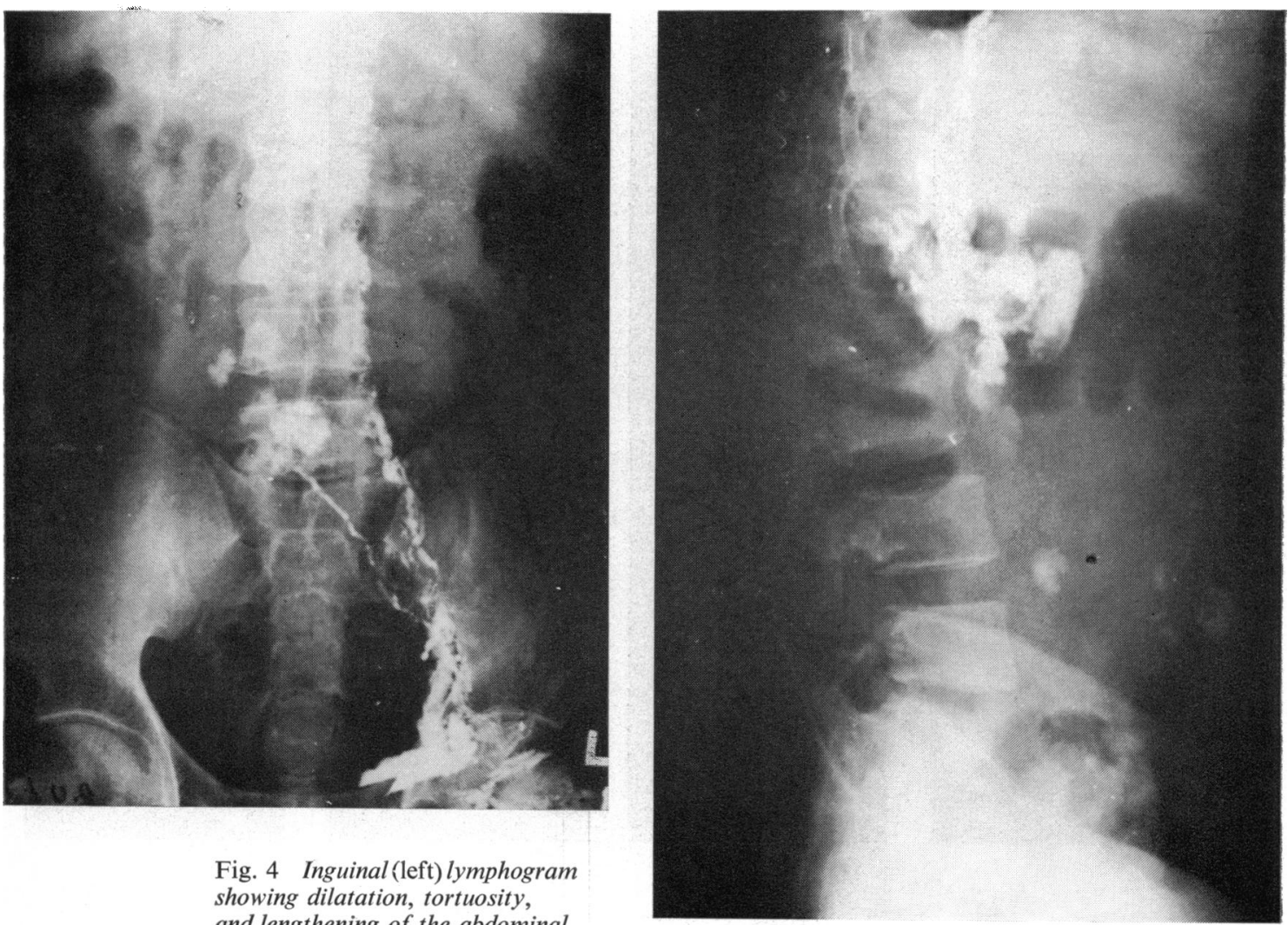

Fig. 4 Inguinal (left) lymphogram showing dilatation, tortuosity, and lengthening of the abdominal lymphatic vessels and retrograde (right) lymphogram showing greatly dilated and tortuous abdominal lymphatics. 


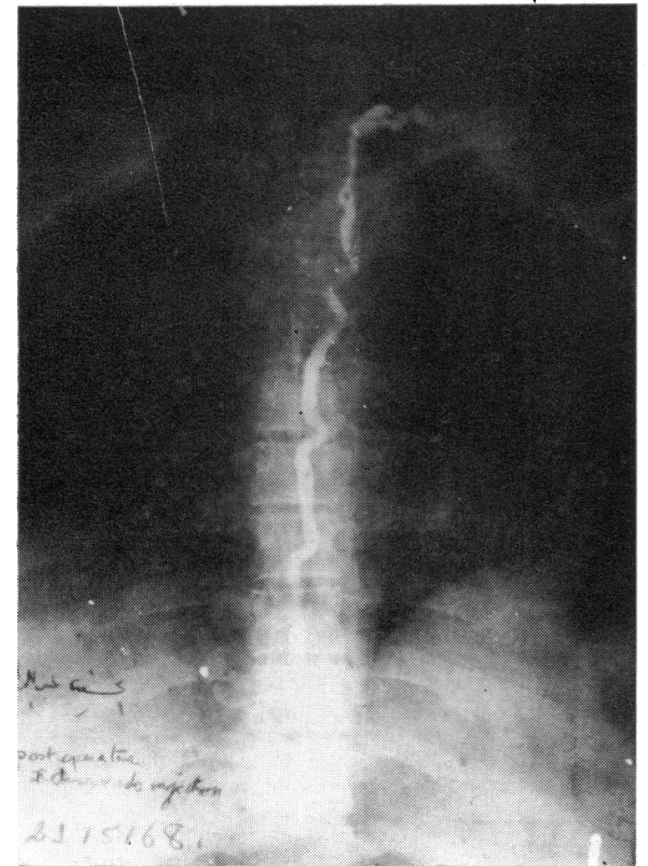

Fig. 5 Retrograde lymphogram of thoracic duct showing dilatation and tortuosity.

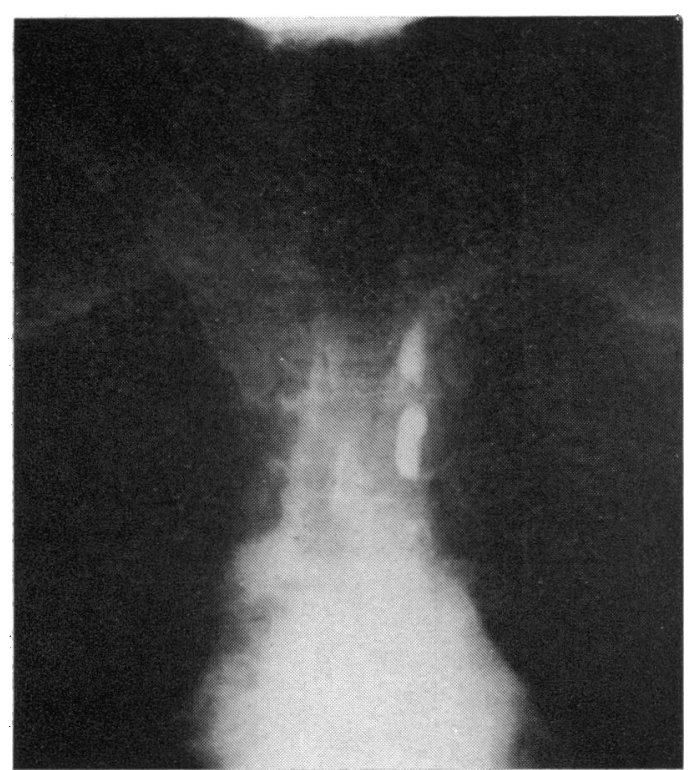

Fig. 6 Lymphogram of ascitic patient showing dilatation of thoracic duct.

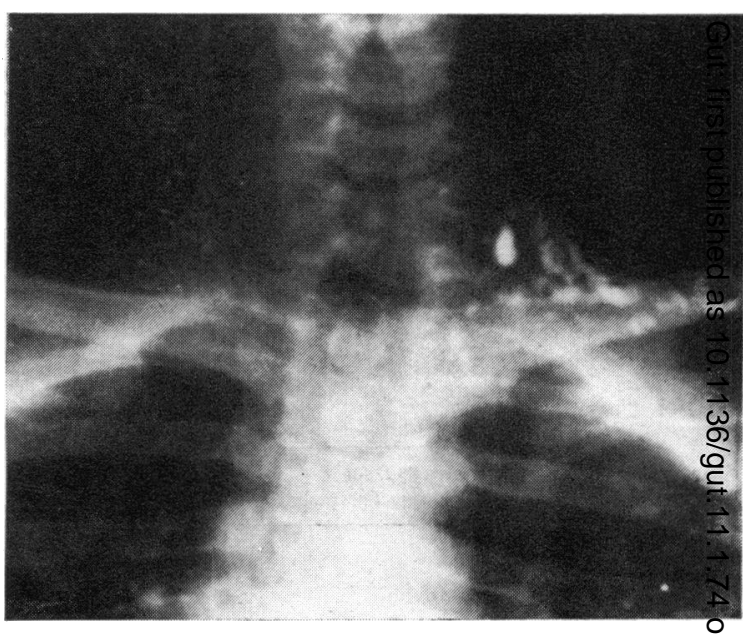

Fig. 7 Lymphogram of the thoracic duct with an angiomatous appearance.

and blood were obtained for analysis. Retrograde lymphangiography was successfully attempted in four cases.

\section{Results}

POSTMORTEM STUDY

The 20 cases of schistosomal hepatic fibrosis showed dilatation of the thoracic duct compared with the 16 cases of cardiac failure and normal controls. Dilatation with tortuosity was maximal in those with ascites. The cases with ascites were grouped into mild, moderate, and severe according to the volume of fluid withdrawn before the dissection of the thoracic duct: 'mild' was defined as less than 3 litres of fluid; moderate as 3-6 litres; and severe more than 6 litres (Fig 1).

Lymphovenous communication was found in two cases; both were of the chronic type with no history of ascites or haematemesis (Fig. 2).

A volumetric study of the isolated thoracic duct showed the maximal increase in severe ascites to be twice to eight times that of normal (Fig. 3).

\section{LYMPHANGIOGRAPHY}

The nodal lymphangiograms in cases of ascites showed the abdominal lymphatics to be dilated and tortuous (Fig. 4). Retrograde lymphangiography of four cases showed the thoracic duct to be dilated and tortuous (Figs. 5 and 6), with an angiomatous appearance in two cases at the termination of the thoracic duct (Fig. 7). 


\section{THORACIC DUCT CANNULATION}

In the 10 cases submitted to operation, the thoracic duct was found to be dilated at its termination. The diameter varied from 0.7 to $1.2 \mathrm{~cm}$, with an average of $0.93 \mathrm{~cm}$. In six cases the lymph was bloody. Table I shows the pressure and flow data obtained in these cases. The increase in pressure was two to fourfold that of normal. Lymph flow varied from 3 to $9 \mathrm{ml} / \mathrm{min}$, with an average of $6.5 \mathrm{ml} / \mathrm{min}$.

\begin{tabular}{lllll}
\hline Case No. & $\begin{array}{l}\text { Thoracic Duct } \\
\text { Occluding Pressure }\end{array}$ & Non-occluding Pressure & $\begin{array}{l}\text { Flow } \\
(\mathrm{ml} / \mathrm{min})\end{array}$ & Character \\
\hline 1 & 50 & - & 5 & Clear \\
2 & 43 & - & 7 & Bloody \\
3 & 60 & - & 9 & Clear \\
4 & 45 & $15 \cdot 5$ & 9 & Bloody \\
5 & 40 & 13 & 8 & Bloody \\
6 & 33 & 7 & 8 & Bloody \\
7 & 7 & - & 5 & Bloody \\
8 & 11 & - & 3 & Clear \\
9 & 45 & 5 & 8 & Bloody \\
10 & 21 & $10 \cdot 1$ & 3 & Clear \\
Mean & $35 \cdot 5$ & 6.5 & \\
\hline
\end{tabular}

Table I Flow and pressure data obtained in 10 thoracic fistula patients.

\section{Discussion}

This work shows that in schistosomal hepatic fibrosis there is an increase in thoracic duct lymph flow rate and pressure. The increased lymph flow is secondary to rise in venous pressure (Szabo, Magyar, and Papp, 1963). In Laennec's cirrhosis, the source of increased lymph production is the liver, as has been shown by many authorities following ligation of the thoracic inferior vena cava (Bolton and Barnard, 1931; Grindlay, Flock, and Bollman, 1948; McKee, Schilling, Tishkoff, and Hyatt, 1949; Volwiler, Bollman, and Grindlars, 1950; Freeman, 1953; Hyatt and Smith, 1954).

No analogous mechanism is present in pure schistosomal hepatic fibrosis with presinusoidal obstruction. Starling (1894) showed that on ligation of the portal vein, a greater flow of lymph was produced, and he pointed out that the site of origin was the gastrointestinal tract. Such a possibility is entertained in cases of schistosomal hepatic fibrosis with ascites.

It is suggested that more lymph is formed in these cases of schistosomal hepatic fibrosis and that if there is a disparity between production and clearance, ascites may be perpetuated or initiated. This is demonstrated in dilatation of the thoracic duct which may be ameliorated by cannulating the thoracic duct.

\section{References}

Allen, L., and Vogt, E. (1937). A mechanism of lymphatic absorption from serous cavities. Amer. J. Physiol., 119, 776-782.

Badawi, M. S., Nomeir, A. M., and Zaher, R. A. (1962). Evaluation of portal hypertension in hepatic schistosomiasis. Alexandria med. J., 8, 220.
Bolton, C. (1921). Absorption from the peritoneal cavity. J. Path. Bact., 24, 429-445.

Bolton, C., and Barnard, W. G. (1931). The pathological occurrences in the liver in experimental venous stagnation. J. Path. Bact., 34, 701-709.

Courtice, F. C., and Steinbeck, A. W. (1950). The rate of absorption of heparinized plasma and of 0.9 p.c. $\mathrm{NACl}$ from the peritoneal cavity of the rabbit and guinea-pig. Aust. $J$. exp. Biol. med. Sci., 28, 171-182.

Courtice, F. C., and Steinbeck, A. W. (1951). The effects of lymphatic obstruction and of posture on the absorption of protein from the peritoneal cavity. Aust. J. exp. Biol. med. Sci., 29, 451-458.

Dumont, A. E., and Mulholland, J. H. (1962). Alterations in thoracic duct lymph flow in hepatic cirrhosis. Ann. Surg., 156, 668-677.

Dumont, A. E., and Witte, M. H. (1966). Significance of excess lymph in the thoracic duct on patients with hepatic cirrhosis. Amer.J. Surg., 112, 401-406.

Freeman, S. (1953). Recent progress in the physiology and biochemistry of the liver. Med.Clin. N. Amer., 37, 109-124.

Grindlay, J. H., Flock, E. V., and Bollman, J. L. (1948). Hepatic lymph and ascitic fluid following experimental chronic obstruction of the inferior vena cava. (Abstr.) Fed. Proc. $7,45$.

Hahn, P. F., Miller, L. L., Robscheit-Robbins, F. S., Bale, W. F., and Whipple, G. H. (1944). Peritoneal absorption. $J$. exp. Med., 80, 77-82.

Hall, R. C., and Krementz, E. T. (1967). Lymphangiography by lymph-node injection. J. Amer. med. Ass., 202, 1136-39.

Higgins, G. M., and Graham, A. S. (1929). Lymphatic drainage from the peritoneal cavity of the dog. Arch. Surg., 19, 453465.

Hyatt, R. E., and Smith, J. R. (1954). The mechanism of ascites. A physiologic appraisal. Amer.J. Med., 16, 434-448.

Hyatt, R. E., Lawrence, G. H., and Smith, J. R. (1955). Observations on the origin of ascites from experimental hepatic congestion. J. Lab. clin. Med., 45, 274-280.

Lemon, W. S., and Higgins, G. M. (1929). Lymphatic absorption of particulate matter through the normal and the paralyzed diaphragm. An experimental study. Amer. J. med. Sci., 178, 536-547.

McKee, F. W., Schilling, J. A., Tishkoff, G. H., and Hyatt, R. E (1949): Experimental ascites. Effects of sodium chloride and protein intake on protein metabolism in dogs with constricted inferior vena cava. Surg. Gynec. Obstet., 89, 529-540.

Madden, J. I , Lore, J. M., Gerold, F. P., and Ravid, J. M. (1954). The pathogenesis of ascites and a consideration of its treatment. Surg. Gynec. Obstet., 99, 385-391.

Ramos, O. L., Saad, F., and Leser, W. P. (1964). Portal hemodynamics and liver cell function in hepatic schistosomiasis. Gastroenterology, 47, 241-247.

Salah, M. (1962). The bilhurzial liver. Alexandria med. J., 8, 177.

Simer, P. H. (1944). The drainage of particulate matter from the peritoneal cavity by lymphatics. Anat. Rec., 88, 175-192.

Simer, P. H. (1948). The passage of particulate matter from the peritoneal cavity into the lymph vessels of the diaphragm. Anat. Rec., 101, 333-351.

Szabo, Gy., Magyar, Z., and Papp, M. (1963). Correlation between capillary filtration and lymph flow in venous congestion. Acta med. Acad. Sci. hung., 19, 185-191.

Starling, E. H. (1894). The influence of mechanical factors on lymph production. J. Physiol. (Lond.), 16, 224-267.

Van Pernis, P. A. (1949). Variations of the thoracic duct. Surgery, 26, 806-809.

Volwiler, W., Bollman, J. L., and Grindlay, J. H. (1950). A comparison of two types of experimental ascites. Proc. Mayo Clin., 25, 31-33. 